\title{
Ligation of patent ductus arteriosus in very low birth- weight premature neonates
}

\author{
PROBAL K GHOSH, J LUBLINER, M MOGILNAR, V YAKIREVICH, \\ BERNARDO A VIDNE
}

From the Department of Thoracic and Cardiovascular Surgery, Ichilov Hospital, Tel-Aviv Medical Center, and Sackler School of Medicine, Tel Aviv University

ABSTRACT The results of ligation of a patent ductus arteriosus in 30 premature neonates with a very low birth weight were analysed. The mean gestational age at birth was 27 weeks and the mean weight $811 \mathrm{~g}$. Attempted closure of the ductus with indomethacin in 19 infants failed, though there was temporary closure in nine. Congestive heart failure was present in 29 and respiratory distress in 22 patients. Endotracheal intubation with assisted ventilation was neccessary in all cases. The mean age at operation was 13.5 days and ductal ligation was performed in the intensive care unit under local anaesthesia supplemented with pancuronium and pethidine. There were no intraoperative deaths, but five infants died in hospital. There were seven late deaths. Eighteen survivors have been followed for a mean of 26.5 months. Early ligation of a patent ductus arteriosus in premature infants with a very low birth weight improved the cardiorespiratory state. Long term follow up showed good clinical progress in two thirds of the surviving group.

Delayed closure of a patent ductus arteriosus in premature neonates ${ }^{1}$ may be a factor in causing congestive heart failure and respiratory distress. ${ }^{23}$ Medical treatment with indomethacin, a prostaglandin synthetase inhibitor, has been used despite reports of a varying response $\mathrm{e}^{-6}$ and the risk of renal insufficiency and gestational bleeding.?

It has been our policy to recommend surgical ligation of a patent ductus arteriosus in premature neonates unresponsive to a short trial of medical treatment for cardiac failure or respiratory distress. In central Israel our cardiovascular surgical unit provides a surgical service to four neonatal intensive care units over an area of 3600 square kilometres. To avoid moving these critically ill infants, the operations were performed in the neonatal intensive care units, which were $40-70 \mathrm{~km}$ from the surgical unit. This report discusses our experience, including the surgical management and follow up of the survivors.

\section{Patients and methods}

Thirty premature neonates (19 of them boys)

Address for reprint requests: Professor BA Vidne, Department of Thoracic and Cardiovascular Surgery, Ichilov Hospital, Tel-Aviv 64239, Israel.

Accepted 29 January 1985 underwent ligation of patent ductus arteriosus during the five years 1979-83. All patients were born in hospital. The mean gestational age was 27.0 (range 23-34) weeks and the mean birthweight was 811 $(650-1620) \mathrm{g}$. Only three infants weighed $1000 \mathrm{~g}$ or more at birth. Racially 16 patients were orientals and 14 Askanazi. The mothers' ages ranged from 20 to 36 (mean 27.7) years and toxaemia of pregnancy had been present in two. Premature rupture of the membranes had occurred in five cases and caesarean section had been performed in six. Abruptio placentae and placenta praevia had each occurred once, and amnionitis had been present in eight mothers.

Cardiac failure was present in 29 neonates. The remaining one suffered from respiratory distress only. All infants were intubated in the neonatal intensive care unit. Arterial pressures and blood gas tensions were monitored. Later in the series transcutaneous oxygen $\left(\mathrm{TcPO}_{2}\right)$ monitoring was available. Cardiac failure was treated with digitalis, diuretics, and fluid restriction in 27 cases, diuretics and fluid restriction in one case, and fluid restriction alone in one. Aminophylline had to be continually administered to eight patients. Respiratory distress was present in 22 patients. The arterial carbon dioxide tension $\left(\mathrm{PaCO}_{2}\right)$ was greater than $60 \mathrm{~mm} \mathrm{Hg}$ and oxygen tension $\left(\mathrm{PaO}_{2}\right)$ less than $50 \mathrm{~mm} \mathrm{Hg}$ with inspired oxygen $\left(\mathrm{FiO}_{2}\right)$ of less than $50 \%$ in these 
Table 1 Preoperative lesions and complications

\begin{tabular}{ll} 
& No of cases \\
\hline Sepsis & 5 \\
Pneumothorax & 2 \\
Pneumonia & 2 \\
Pulmonary haemorrhage & 3 \\
Intracranial haemorrhage & 1 \\
Hyperbilirubinaemia & 12 \\
$\quad$ (9 required exchange transfusion) & 4 \\
Renal failure & \\
Inappropriate antidiuretic hormone & 1 \\
syndrome & 1 \\
Psychomotor retardation & 1 \\
Cerebral palsy & 3 \\
\hline
\end{tabular}

infants. The apnoea bradycardia syndrome was present in 14 patients, who were treated with isoprenaline, atropine, and assisted ventilation, alone or in combination.

The patients were assessed for the presence of a haemodynamically important patent ductus arteriosus by an aggregate diagnostic scheme of first order and second order criteria and additional clinical findings, described by the National Collaborative Study on patent ductus arteriosus in premature infants. ${ }^{8}$ Bounding pulses and a hyperdynamic praecordium were present in 29 of the 30 patients; a continuous murmur was present in four, a systolic murmur in 24 , and no murmur in two patients. In addition to the ventilatory criteria, these "silent ductuses" had positive chest radiographic findings to confirm their haemodynamic importance.

Chest radiographs showed cardiomegaly in 18, pulmonary plethora in 14 , and perihilar oedema in 22 patients. Significantly, the early changes of bronchopulmonary dysplasia were present in 10 and a preoperative pneumothorax in two patients. Cardiac catheterisation was done only in the first patient in the study and echocardiography was not performed. Pulmonic stenosis was suspected in one patient and ventricular septal defect in another. Preoperative systemic lesions and complications are detailed in table 1.

After the diagnosis of a haemodynamically significant patent ductus arteriosus was made, a trial of medical therapy was attempted to wean the patient from the respirator. Indomethacin was administered to 19 patients. In the remaining 11 it could not be used because of hypercreatinaemia in 8; pulmonary haemorrhage in one; cephalhaematoma, cholestatic jaundice, renal failure and haemoperitoneum in one; and unavailability in two patients. One patient had both hypercreatinaemia and pulmonary haemorrhage. Respiratory distress did not improve in any of the 19 patients who received indomenthacin. Despite temporary ductus closure in nine patients the development of throm- bocytopenia in two and hypercreatinaemia in one patient led to the abandonment of indomethacin therapy.

Surgical ligation was performed once medical treatment had failed. At the time of operation the mean age was 17 (range 4-42) days and the mean weight 842 (range 650-1320) g. Only three patients weighed more than $1000 \mathrm{~g}$.

The first patient in this series was moved to the operating room for ligation of patent ductus arteriosus, but all other patients were operated on in a partitioned area in the neonatal intensive care unit. All essential personnel were masked and gowned. Sterile gowns, drapes, and instruments brought from the operating theatre were used to maintain a sterile field and avoid contamination. General anaesthesia with nitrous oxide and oxygen was used only in the first patient. All others were operated on under intravenous pethidine, atropine, and pancuronium. Xylocaine $0.5 \%$ was infiltrated locally and surgical ligation of the patent ductus arteriosus was performed with $2-0$ silk through a left posterolateral fourth interspace thoracotomy. An Ethicon LC-200 medium size haemoclip was used for ductal obliteration in the last patient of the series. All babies had a left chest drain for 12-48 hours.

The size of the ductus did not show any correlation with the preoperative clinical state, gestational age, or the presence or absence of respiratory distress or cardiomegaly. It was as large as the aorta in six cases and two thirds of the aortic diameter in 14 , half in five, and one third in five.

\section{Operative results and complications}

No neonate died as a direct result of anaesthesia or the operative procedure. Two patients died in the first 28 days of life, resulting in a neonatal mortality rate of $6.6 \%$. The hospital mortality was $16.6 \%$ (five patients). Seven babies died from two to seven months after operation.

Respiratory failure caused three of the hospital deaths. Preoperative bronchopulmonary dysplasia was noticed in two and pulmonary haemorrhage in the third. A fourth baby died from sepsis and extensive intravascular thrombosis and the fifth from intracranial haemorrhage, renal failure, and sepsis. Sepsis was present before operation in both of these. Intracranial haemorrhage caused two late deaths. Two other babies succumbed during spells of bradycardia three and a half and six and a half months after operation. The remaining three infants died from respiratory failure. Preoperative bronchopulmonary dysplasia and postoperative sepsis had been present in three of them. 
Table 2 Complications in those who died

\begin{tabular}{ll}
\hline & No of cases \\
\hline Sepsis & 5 \\
Pneumothorax & 9 \\
Pneumonia & 5 \\
Bronchopulmonary dysplasia & 5 \\
Apnoea bradycardia & 5 \\
Intracranial haemorrhage & 2 \\
Renal failure & 2 \\
Necrotising enterocolitis & 2 \\
Recurrent laryngeal nerve paralysis & 1 \\
\hline
\end{tabular}

Thus preoperative bronchopulmonary dysplasia unaffected by ductal ligation was a factor in five out of the total 12 deaths. Sepsis due to an immature immune system was an important factor in five of the deaths.

The mean age at operation was 16 days for those who survived and 21 days for those who did not. The mean weight at operation was $835.5 \mathrm{~g}$ for the survivors and $835.6 \mathrm{~g}$ for those who died. These differences are not statistically significant. The significance of a birth weight of more than $1000 \mathrm{~g}$ could not be assessed as there were only three neonates in this group. Associated complications in those who died are shown in table 2 .

The complications in the survivors are shown in table 3. Eighteen were followed up for three months to five years (mean 26.5 months). Follow up assessment combined the use of the Amiel Tison first year neurological examination coupled with the Bayley scales of infant development whenever possible. Ophthalmological examination when indicated included fundoscopy and cycloplegic refraction. Free field audiological tests were done when abnormalities were suspected.

Recurrence of patent ductus arteriosus was noticed in two patients. Bronchopulmonary dysplasia was found to continue in six of the survivors. One developed cor pulmonale and the other lobar emphysema. Three infants developed retrolental fibroplasia and two required cryosurgery. Rickets developed in five of them and was corrected with medical treatment. Subglottic stenosis occurred in

Table 3 Complications in survivors

\begin{tabular}{ll}
\hline & No of cases \\
\hline Sepsis & 8 \\
Recurrent pneumothorax & 5 \\
Pneumonia & 6 \\
Bronchopulmonary dysplasia & 6 \\
Apnoea bradycardia & 7 \\
Intracranial haemorrhage & 1 \\
Recurrent patent ductus arteriosus & 2 \\
Necrotising enterocolitis & 2 \\
Rickets & 5 \\
\hline
\end{tabular}

one patient. Intracranial bleeding led to ventriculitis in one patient, who required a ventriculoperitoneal shunt. Cerebral palsy with psychomotor retardation and pseudotumour cerebri with a convulsive disorder each occurred in one child. Two patients were mentally retarded.

\section{Discussion}

The best location for surgical ligation of a patent ductus arteriosus in neonates has been debated in published reports. A proper operating room has been preferred by many, ${ }^{4-11}$ but several centres now prefer to eliminate the problems of transportation to an operating theatre and thus avoid the risks of thermoregulatory instability, loss of intravenous lines, malfunction and accidental discontinuity of monitoring, improper ventilation, possible airway loss, and underhydration or overhydration with fluids. ${ }^{12-16}$ In the neonatal intensive care unit the neonate is already intubated and on a respirator, venous lines and umbilical arterial cathether are in place, and monitors are already connected for heart rate, respiratory rate, body temperature, and arterial pressure. Comparison of the results of these two groups show no advantage of patent ductus arteriosus ligation in the operating theatre. We preferred to minimise the risks in these critically ill babies and adopted the policy of operating in the neonatal intensive care unit.

One of the main advantages is in maintaining normothermia, which is easier in the partioned area in the NICU than in the operating theatre. All of our patients were maintained at $36-38^{\circ} \mathrm{C}$. The isolettes on which they were placed for the operation had temperature control. The ambient temperature of the room was usually $38^{\circ} \mathrm{C}$. Heating lamps, warming blankets, and wrapping of the extremities and head with sheet wadding were used. All transfusates and infusates were warmed to body temperature before administration.

There is no unanimous agreement about the ideal anaesthetic management of these neonates. Most anaesthetists prefer to avoid or use sparingly the potent inhalation anaesthetics. Nitrous oxide causes myocardial depression. ${ }^{17}$ Despite this, the combination of nitrous oxide with oxygen with or without relaxants and narcotics has been used by many for general anaesthesia. ${ }^{1814}$ Lipman et al ${ }^{20}$ reported a series of 24 patients who had had oxygen, succinylcholine, and local anaesthetics. Robinson and Gregory $^{21}$ reported the use of fentanyl and pancuronium combined with oxygen and air, which produced minimal circulatory disturbances. A ketamine, pancuronium, oxygen, and air combination has also been suggested in published reports. We used 
pethidine, atropine, pancuronium, oxygen, air, and local anaesthetic in combination, on the hypothesis that this would cause minimal circulatory disturbance with effective control of pain. Absence of intraoperative bradycardia and hypoxia (checked by continuous $\mathrm{TcPO}_{2}$ monitoring) supported our hypothesis. There was no postoperative complication that could be attributed to anaesthetic management.

Optimal oxygenation during operation means maintaining oxygenation within a very narrow range and $\mathrm{TcPO}_{2}$ monitoring provides excellent indication of control. During brief spells of vigorous lung retraction $100 \%$ oxygen has to be administered to prevent bradycardia. Though hypoxia is generally more damaging than hyperoxia, Betts et al ${ }^{22}$ correlated the late development of retrolental fibroplasia with brief periods of hyperoxygenation during general anaesthesia.

Several factors have been evaluated as predictors of patients' progress and prognosis. Gay et al $^{23}$ correlated large shunt duration with survival and the late development of bronchopulmonary dysplasia. Clarke $e a^{24}$ analysed their data and those of nine other series and concluded that in respirator dependent neonates with respiratory distress and patent ductus arteriosus the shorter the large shunt duration the lower the mortality rate. They concluded that a large shunt duration of more than eight days significantly increased the mortality rate. We did not find any correlation of large shunt duration of eight days with survival and the late development of bronchopulmonary dysplasia in our patients. Clarke's group further observed a correlation of the average $\mathrm{FiO}_{2}$ requirement with the development of bronchopulmonary dysplasia, the $\mathrm{FiO}_{2}$ requirement being appreciably less in patients without dysplasia. We did not notice any such correlation among our survivors.

Early ductal ligation resulted in a shorter period of intubation, in patients weighing less than $1500 \mathrm{~g}$, than was possible in the medical treatment group in the series reported by Mikhail et al. ${ }^{10}$ Our experience corroborates that. Contrary to their other conclusion, however, early ligation was not found to influence the progress of bronchopulmonary dysplasia if this was already present before operation. ${ }^{23}{ }^{25} 26$ Hall et $\boldsymbol{a l}^{27}$ found chronic lung disease, in many cases with cor pulmonale, in six of their 14 long term survivors. Apparently ligation of the patent ductus arteriosus did not reverse or arrest the progress of lung disease in those patients. Brandt and coworkers ${ }^{28}$ in a late follow up (after one to five years) of 51 survivors found radiographic evidence of bronchopulmonary dysplasia in 17 patients $(34 \%)$ and no residual sequelae were noticed in only
24 survivors (less than $50 \%$ ). This perhaps puts the role of surgical intervention in its proper perspective. This is no "miracle cure in babies with marginal hope for a normal life." ${ }^{24}$ It does, however, increase the quantity of life in these sick neonates who may not otherwise survive at all.

The role of patent ductus arteriosus ligation differs considerably in premature babies with and without respiratory distress. ${ }^{25}{ }^{30}$ In eight out of 30 patients in our study who had no preoperative respiratory distress only two died. One succumbed three and a half months after operation at the age of 128 days owing to a spell of bradycardia. The second died from intracranial haemorrhage and sepsis 38 days after operation. All others had a rapid recovery and left hospital.

The influence of patent ductus arteriosus on pulmonary mechanics, gas exchange, and evolution of bronchopulmonary dysplasia remains undefined. Ductal patency possibly does not decompress a hypertensive pulmonary vascular bed.30 Rudolph and coworkers ${ }^{31}$ showed low pulmonary and systemic arterial pressures in critically ill premature neonates with respiratory distress. Most of their patients had a dominant left to right shunt, though a mixed shunt was reported in some. Levitsky et al ${ }^{31}$ noted that even patients with a small shunt that is not necessarily large enough to increase the size of the left atrium will show a decrease in pulmonary compliance. Coran and colleagues ${ }^{25}$ support the observations of Rudolph's group. Possibly large left to right shunts continue to cause pulmonary damage after causing left heart failure. Left atrial volume overload raises pulmonary venous and capillary pressures, resulting in alveolar transudation and impaired gas exchange. Aggravated ventilationperfusion inequality results in reduction of lung compliance. This leads to further decreased oxygenation and impairment of an already stressed left ventricle. Whether ductal interruption may reverse the process at this stage has not yet been determined. In our follow up of 18 long term survivors persistent bronchopulmonary dysplasia was noticed in six, of whom five had it before operation. Apparently surgical ligation neither reversed nor influenced the dysplasia in these babies.

\section{References}

1 Burnard ED. A murmur that may rise from the ductus arteriosus in the human body. Proc $R$ Soc Med 1959;52:77.

2 Girling DJ, Hallidie-Smith KA. Persistent ductus arteriosus in ill and premature babies. Arch Dis Child 1971;46:177-81.

3 Kitterman JA. Patent ductus arteriosus: current clinical status. Arch Dis Child 1980;55:106-9. 
4 Friedman WF, Hirschklau MJ, Printz MP, Pitlick PT, Kirkpatrick PT. Pharmacologic closure of patent ductus arteriosus in the premature infant. $N$ Engl J Med 1976;295:526-9.

5 Heyman MA, Rudolph AM, Silverman NH. Closure of ductus arteriosus in premature infants by inhibition of prostaglandin synthesis. $N$ Engl J Med 1976; 295:530-3.

6 Neal WA, Kyle JM, Mullett MD. Failure of indomethacin therapy to induce closure of patent ductus arteriosus in premature infants with respiratory distress syndrome. J Pediatr 1977;91:621-3.

7 Friedman Z, Whitman V, Maisels MJ, Berman W jun, Marks KH, Vessell ES. Indomethacin disposition and indomethacin-induced platelet dysfunction in premature infants. J Clin Pharmacol 1978;18:272-9.

8 Ellison RC, Peckham GJ, Lang P, et al. Evaluation of the preterm infant for the patent ductus arteriosus. Pediatrics 1983;71:364-72.

9 Rittenhouse EA. A rational approach to patent ductus arteriosus in neonates. Chest 1979; 75:652.

10 Mikhail M, Lee W, Toews W, et al. Surgical and medical experience with 734 premature infants with patent ductus arteriosus. J Thorac Cardiovasc Surg 1982;83:349-57.

11 Scarano VR. Ligation of patent ductus arteriosus in the neonate. Chest 1980;77:248.

12 Mavroudis C, Cook LN, Fleischaker JW, et al. Management of patent ductus arteriosus in the premature infant: indomethacin versus ligation. Ann Thorac Surg 1983; 36:561-6.

13 Oxnard SC, McGough EC, Jung AL, Ruttenberg HD. Ligation of the patent ductus arteriosus in the newborn intensive care unit. Ann Thorac Surg 1977;23:564-7.

14 Salomon NW, Anderson RM, Copeland JG, Allen HD, Goldberg SJ, Sahn DJ.. A rational approach to ligation of patent ductus arteriosus in the neonate. Chest 1979;75:671-4.

15 Jennings RB jun, Innes BJ, Wirth FH, Askew QA. Bedside patent ductus ligation in prematures. Circulation 1975;52, suppl 2:101.

16 Giradet RE. Ann Thorac Surg 1981;32:171 (in discussion of ref 33).

17 Eisele JH, Smith TY. Cardiovascular effects of $40 \%$ nitrous oxide in man. Anesth Analg 1972;51:956-61.

18 Newman GC, Hansen DD. The anaesthetic management of preterm infants undergoing ligation of patent ductus arteriosus. Can Anaesth Soc J 1980;27:248-53.
19 Finucane BT, Symbas PN, Braswell R. Ligation of patent ductus arteriosus in premature neonates: anaesthetic mangement. South Med J 1981;74:21-3.

20 Lipman M, Nelson RJ, Emmanouilides GC, et al. Ligation of patent ductus arteriosus in premature infants. Br J Anaesth 1976;48:365-9.

21 Robinson S, Gregory GA. Fentanyl-air/ $\mathrm{O}_{2}$ anaesthesia for PDA ligation in infants less than $1500 \mathrm{~g}$. Anaesth Analg 1980;59:556-7 (abstract).

22 Betts EK, Downes JJ, Schaffer DB, et al. Retrolental fibroplasia and oxygen administration during general anaesthesia. Anaesthesiology 1977;47:518-20.

23 Gay JH, Daily WJR, Meyer BHP, Trump DS, Cloud DT, Molthan ME. Ligation of the patent ductus arteriosus in premature infants: report of forty-five cases. J Pediatr Surg 1973;8:677-83.

24 Clarke DR, Paton BC, Way GL, Stewart JR. Patent ductus arteriosus ligation and respiratory distress syndrome in premature infants. Ann Thorac Surg 1976;22:138-45.

25 Coran AG, Cabal L, Siassi B, Rosenkrantz JG. Surgical closure of patent ductus arteriosus in the premature infant with respiratory distress. J Pediatr Sug 1975; 10:399.

26 Siassi B, Blanco C, Cabal LA, Coran AG. Incidence and clinical features of patent ductus arteriosus in low birthweight infants: a prospective analysis of 150 consecutively born infants. Pediatrics 1976;57:347-51.

27 Hall GS, Helmsworth JA, Schreiber JT, et al. Premature infants with patent ductus arteriosus and respiratory distress: selection for ductal ligation. Ann Thorac Surg 1976;22: 146-50.

28 Brandt B III, Marvin WJ, Ehrenhaft JL, Heiztz S, Doty DB. Ligation of patent ductus arteriosus in premature infants. Ann Thorac Surg 1981;32:167-72.

29 Stiles QR. Ann Thorac Surg 1981;32:171 (in discussion of ref 33 ).

30 Williams WH, Gelband H, Bancalari E, et al. The ductus debate: ligation in prematurity? Ann Thorac Surg 1976;22: 161-6.

31 Rudolph AM, Drobaugh JE, Auld PAM, et al. Studies on the circulation in the neonatal period: the circulation in the respiratory distress syndrome. Pediatrics 1961;27:551-66.

32 Levitsky S, Fisher E, Vidyasagar D, et al. Interruption of patent ductus arteriosus in premature infants with respiratory distress syndrome. Ann Thorac Surg 1976;22:131-7. 